\title{
Revisão integrativa sobre biologia, qualidade da água e a ordem Odonata
}

\author{
Integrative review on biology, water quality and the order Odonata \\ Revisión integrativa sobre biología, calidad del agua y orden Odonata
}

\author{
Annanda Gabriely Moura de Souza \\ ORCID: https://orcid.org/0000-0002-0621-0784 \\ Universidade do Estado do Pará, Brasil \\ E-mail: annanda.annandasouza@gmail.com \\ Vito de Jesus Lameira Neto \\ ORCID: https://orcid.org/0000-0001-8363-1438 \\ Universidade do Estado do Pará, Brasil \\ E-mail: www.vitto@gmail.com \\ Antônio Pereira Júnior \\ ORCID: https://orcid.org/0000-0001-6241-985X \\ Universidade do Estado do Pará, Brasil \\ E-mail: antonio.junior@uepa.br
}

\begin{abstract}
Resumo
Ciências como a Biologia geram informações acerca dos ecossistemas como, por exemplo, os aquáticos, além de promover uma integração com os conhecimentos étnicos associados à Botânica. O objetivo deste trabalho foi a realização de uma revisão integrativa a respeito da inter-relação da biologia com diversas áreas ambientais, sob dois aspectos, a conservação e o equilíbrio, para investigar a relação entre biologia e as pesquisas sobre a qualidade da água e o uso da ordem Odonata como bioindicadora da qualidade ambiental de corpos hídricos. O método utilizado foi o dedutivo associado a uma abordagem quantitativa e qualitativa de natureza básica. Os dados obtidos e analisados indicaram que os termos biológicos estão presentes na maioria das literaturas selecionadas ( $n=46,2 \%)$; em relação à qualidade da água, houve uma pequena redução $(n=30,8 \%)$; o uso da ordem Odonata como bioindicadora da qualidade da água ainda é parco $(n=22,9 \%)$. Quanto ao emprego de descritores nas pesquisas analisadas, foram identificadas as citações: "Termos biológicos e Qualidade da água" ( $n=65,8 \%)$; "Odonata e Qualidade da água" ( $n=$ $21,1 \%)$; "Termos biológicos e Odonata" $(n=13,2 \%)$. A ordem Odonata, como bioindicadora, está em evolução $(\Sigma=$ $33,3 \%)$ e com frequência elevada $(f r>50 \%)$ quando comparada à aplicação dos Termos biológicos e Qualidade da água. Então, a aplicação da biologia já é efetiva em áreas ambientais como análise da qualidade da água. Já o uso da ordem Odonata como bioindicadora da qualidade da água ainda não é empregado com muita frequência. Com isso, é recomendado que haja uma maior apreciação dos pesquisadores quanto a essa relação, o que poderá contribuir para a qualificação e o monitoramento desse recurso natural com mais abrangência e eficácia.
\end{abstract}

Palavras-chave: Indicação efetiva; Invertebrados aquáticos; Recursos hídricos.

\begin{abstract}
Sciences such as biology generate information about ecosystems, such as aquatic ecosystems, and promote integration with ethnic knowledge associated with botany. The objective of this work was to carry out an integrative review about the interrelationship of biology with various environmental areas, under two aspects, conservation, and balance, to investigate the relationship between biology and research on water quality and the use of the order Odonata as bioindicator of the environmental quality of water bodies. The research method was deductively associated with a quantitative and qualitative approach of a basic nature. The data obtained and analyzed indicated that the biological terms are present in most of the selected literature $(n=46.2 \%)$; regarding water quality, there was a small reduction ( $n$ $=30.8 \%)$; the use of the order Odonata as bioindicators of water quality is still scarce $(\mathrm{n}=22.9 \%)$. As for the use of descriptors in the analyzed research, the following citations were identified: "Biological terms and water quality" ( $\mathrm{n}=$ $65.8 \%)$; "Odonata and water quality" ( $\mathrm{n}=21.1 \%)$; "Biological terms and Odonata" $(\mathrm{n}=13.2 \%)$. The order Odonata, as a bioindicator, is evolving $(\Sigma=33.3 \%)$ and with high frequency ( $\mathrm{fr}>50 \%)$ when compared to the application of Biological Terms and Water Quality. So, the application of biology is already effective in environmental areas such as water quality analysis. However, the use of Odonata as bioindicators of water quality is not used very often yet. Thus, it is recommended that there is a greater appreciation by researchers of this relationship, which can contribute to the qualification and monitoring of this natural resource more comprehensively and effectively.
\end{abstract}

Keywords: Effective indication; Aquatic invertebrates; Water resources. 


\begin{abstract}
Resumen
Ciencias como la Biología generan información sobre los ecosistemas (por ejemplo, acuáticos), además de promover una integración con los conocimientos étnicos asociados a la Botánica. El objetivo de este trabajo fue realizar una revisión integradora sobre la interrelación de la biología con diversas áreas ambientales (conservación/equilibrio) para investigar: 1) la relación entre la biología y la investigación sobre la calidad del agua; 2) el uso del orden Odonata como bioindicador de masas de agua. El método de investigación fue el deductivo asociado a un enfoque cuantitativo y cualitativo, de carácter básico. Los datos obtenidos y analizados indicaron que los términos biológicos están presentes en la mayoría de las literaturas seleccionadas $(n=46,2 \%)$; en relación con la calidad del agua, hubo una pequeña reducción $(\mathrm{n}=30,8 \%)$; el uso del orden Odonata como bioindicador de la calidad del agua sigue siendo escaso $(\mathrm{n}=22,9 \%)$. En cuanto al uso de descriptores en las investigaciones analizadas, se identificaron las siguientes citas: "Términos biológicos y calidad del agua" $(n=65,8 \%)$; "Odonatos y calidad del agua" $(n=21,1 \%)$; "Términos biológicos y Odonatos" $(n=13,2 \%)$. El Orden Odonata como bioindicador, está evolucionando $(\Sigma=33,3 \%)$ y con alta frecuencia $(f r>50 \%)$, cuando se compara con la aplicación de Términos biológicos y Calidad del agua. Entonces, la aplicación de la biología ya es efectiva en áreas ambientales como el análisis de la calidad del agua. El uso del orden Odonata como bioindicador de la calidad del agua todavía no se utiliza con mucha frecuencia. Por ello, se recomienda que exista una mayor apreciación de los investigadores respecto a esta relación, lo que puede contribuir a la calificación y seguimiento de este recurso natural con mayor alcance y efectividad.
\end{abstract}

Palabras clave: Indicación efectiva; Invertebrados acuáticos; Recursos hídricos.

\title{
1. Introdução
}

A área ambiental, cujas informações principais são advindas da biologia, tem incrementado informações acerca do estado de conservação/equilíbrio da natureza. Essas informações são expostas principalmente à comunidade acadêmica a partir do elevado número de publicações sobre essa inter-relação. Para graduandos, isso torna difícil perceber qual é o artifício mais efetivo a ser empregado na pesquisa científica, como a revisão integrativa, por exemplo (Souza et al., 2010).

Ainda de acordo com as autoras, essa categoria de revisão proporciona a construção de uma síntese do conhecimento em questão para poder ser aplicado em outros estudos, com prioridade na obtenção de dados finais significativos. Quanto à efetividade desse método para pesquisa, é importante que ela seja baseada em evidências que podem ser obtidas em fontes de literaturas sobre o tema, por isso, esse método permite a construção de hipóteses, diferentes referenciais teóricos e metodológicos e, consequentemente, o desenvolvimento de teorias mais modernas (Soares et al., 2014).

Tais argumentações constroem embasamentos que permitem associar as alterações ambientais, independente do meio onde ocorram, com a necessidade de um conhecimento mais profícuo da Biologia, já que a percepção delas está acoplada às áreas distintas dessa ciência, como a Ecologia, a Botânica e a Zoologia. Por isso, a exploração dos recursos naturais (Ex.: água) tem consequências negativas à saúde da comunidade e compromete a biodiversidade (Zanella, 2012).

Esses desequilíbrios são provocados em sua maioria pelos seres humanos, já que eles são usuários dos ambientes sob inúmeros aspectos como o uso e ocupação do solo e, com essa ação, provocam uma entropia neg ativa. Os efeitos disso foram observados por Schrödinger em 1986. Ele escreveu que a biologia exclui aspectos comportamentais éticos e a ecologia se preocupa com o sentimento conservacionista do meio em relação ao consumo do que "eu preciso", ou seja, a simples troca de matéria e energia é determinante do fenômeno vital: a vida (Branco, 1995).

Em relação a esses desequilíbrios, especialmente no meio hídrico (propriedades físicas, químicas e biológicas), as consequências são drásticas para a diversidade tanto da flora quanto da fauna e para a qualidade da água. A perda da segunda está associada ao crescimento populacional e urbano, pois os rios que perpassam pelas cidades e municípios estão com as margens habitadas - é notável o aumento das construções de rodovias nesses espaços - e muitas vezes servem como depósito residual e receptor de efluentes domésticos, o que contribui com as cargas poluitivas que adentram esses rios (Silva et al., 2018).

Tais cargas poluitivas preocupam os gestores de muitas cidades, porque a qualidade da água desses corpos hídricos está cada vez mais deteriorada e sem condições para o abastecimento público, que é um desafio de grandes proporções, principalmente quando este rio é o manancial do município (Anelli, 2015). Estas cargas podem ser detectadas por uma das 
ferramentas disponíveis nesse ambiente: os organismos bioindicadores, na maioria invertebrados, que possuem uma capacidade auto perceptiva quanto ao desequilíbrio do meio bem elevada, devido à presença do sistema sensorial (Oliveira et al., 2014).

Dentre tantos bioindicadores, destacam-se as ninfas de Odonata pertencentes a um grupo variado de insetos. Estes apresentam fase larval aquática, por isso são utilizados na bioindicação da qualidade ambiental devido à sensibilidade às variações hídricas, especialmente a concentração de oxigênio dissolvido (OD). Logo, estão no grupo dos invertebrados intolerantes à poluição (Pereira, 2012). Além disso, tanto a larva quanto os adultos são predadores, o que contribui para a manutenção do equilíbrio ambiental, visto que se situam em níveis elevados na cadeia trófica (Neiss, 2012).

$\mathrm{Na}$ ordem Odonata, tem-se a ocorrência das libélulas que habitam as proximidades de corpos hídricos lóticos onde a água pode ser abundante ou escassa, além de ter como habitat vegetais, como os bambus (Bambusa sp.) ou estruturas componentes desse ou de outros vegetais aquáticos (ex.: caules, frutos, e axilas de plantas) devido à presença da água que é essencial ao desenvolvimento delas (Godé \& Peruquetti, 2015).

A respeito desses indivíduos como bioindicadores, os estudos já publicados (Garcia Junior et al., 2019; Pimenta et al., 2016) são conclusivos quanto ao uso de insetos aquáticos, porque oferecem respostas mais sutis a mudanças ambientais (ex.: variação de temperatura da água; $\mathrm{pH}$, dentre outros) nesses ecossistemas aquáticos a partir da presença ou da ausência deles em corpos hídricos analisados. Outra função desses seres vivos no meio ambiente é a atuação deles como controladores de vetores, que podem incrementar as notificações de doenças como a dengue, pois as ninfas de Odonata alimentam-se de ovos do Aedes aegypti atestando que elas possuem uma eficiência média de predação e, com isso, diminuem a proliferação desses agentes transmissores daquela patologia (Silva Filho, 2017).

Como não se pode conter a urbanização e a contaminação de rios urbanos utilizados como mananciais, há a possibilidade de melhorar a análise da qualidade da água com a associação da presença ou ausência de Odonata, o que justificou este estudo e incrementou a relevância dele, além de permitir estabelecer o objetivo que foi encontrar respostas para duas indagações: 1) a biologia tem sido utilizada como ferramenta de análise ambiental da água? Como? 2) Odonata é um bioindicador utilizado nesses casos?

\section{Material e métodos}

O método utilizado foi o dedutivo-integrativo com natureza básica e a abrangência quantitativa e qualitativa, adaptada a partir de sínteses sobre metodologias da pesquisa cientifica já publicadas por catedráticos nessa área (Quadro 1).

Quadro 1. Sínteses que permitiram elaborar a metodologia dessa pesquisa.

\begin{tabular}{|c|c|l|}
\hline Autor(es) & $\begin{array}{c}\text { Ano da } \\
\text { publicação }\end{array}$ & \multicolumn{1}{c|}{ Sínteses } \\
\hline $\begin{array}{c}\text { Botelho et } \\
\text { al. }\end{array}$ & 2011 & $\begin{array}{l}\text { A revisão integrativa permite uma análise do conhecimento já construído para um determinado } \\
\text { tema, e nele se evidencia a importância na construção da ciência. }\end{array}$ \\
\hline $\begin{array}{c}\text { Camargo } \\
\text { et al. }\end{array}$ & 2018 & $\begin{array}{l}\text { "A revisão integrativa permite uma avaliação critica das evidências encontradas e a } \\
\text { caracterização do estado do conhecimento do assunto de interesse (p.2150)”. }\end{array}$ \\
\hline $\begin{array}{c}\text { Lakatos } \\
\& \\
\text { Marconi }\end{array}$ & 2017 & A busca por fontes já publicadas possui evidências similares ao objeto da pesquisa. \\
\hline $\begin{array}{c}\text { Pereira et } \\
\text { al. }\end{array}$ & 2018 & $\begin{array}{l}\text { O método dedutivo considera fenômenos particulares (o homem como poluidor da água); a } \\
\text { formulação de hipóteses: 1- as ações antrópicas alteram funcionalmente os corpos hídricos; 2- a } \\
\text { correlação entre bioindicadores e parâmetros mensuráveis da água (físicos, químicos e } \\
\text { biológicos), bem como permite abordagens tanto quantitativa quanto qualitativa. }\end{array}$ \\
\hline
\end{tabular}

Fonte: Autores (2021). 
Para complementar esse método, foram realizadas sete etapas, onde cada uma delas permitiu uma melhor estruturação dessa revisão (Quadro 2).

Quadro 2. Etapas e ações realizadas para a elaboração da revisão integrativa.

\begin{tabular}{|c|c|}
\hline Etapas & Ações \\
\hline 1 & $\begin{array}{l}\text { Estabelecimento do recorte temporal ( } 2008 \text { a 2021) acerca do tema, com ênfase aos últimos cinco anos ( } 2017 \text { a } \\
\text { 2021). Justifica-se essa temporalidade como fator para o uso de dados mais recentes. Excetuam-se os trabalhos } \\
\text { pioneiros e as legislações pertinentes. }\end{array}$ \\
\hline 2 & $\begin{array}{l}\text { 2.1) Acesso em cinco links eletrônicos para seleção de periódicos: Portal de periódicos da Coordenação de } \\
\text { Pesquisa e Ensino Superior (CAPES), Direct Science, Scientific Eletronic Library Online (SciELO), } \\
\text { Research, Society and Development, Web of Science. } \\
\text { 2.2) A seleção ocorreu a partir da presença de pelo menos um dos três descritores identificadores dessa revisão } \\
\text { integrativa: termos biológicos, qualidade da água e Odonata. } \\
\text { 2.3) Identificação do(s) mais prolífero(s) no recorte temporal estabelecido para analisar a evolução dos estudos } \\
\text { com base no tema dessa revisão. }\end{array}$ \\
\hline 3 & $\begin{array}{l}\text { Pré-seleção da literatura: constatar a presença desses descritores nas publicações contidas nos periódicos em } \\
\text { congressos, nos trabalhos de conclusão de curso, dissertações, teses e monografias em três seções: título, resumo e } \\
\text { palavras-chave para identificar a presença de, pelo menos, um deles; livros e capítulos: título. }\end{array}$ \\
\hline 4 & $\begin{array}{l}\text { Fez-se a identificação das palavras de maior frequência naquelas seções para definição dos descritores seletivos } \\
\text { finais, de acordo com o estabelecido pela de Zipf ou Lei no Menor esforço (Maia, 1973). Em seguida, elas foram } \\
\text { listadas na ordem das frequências contidas nas três seções analisadas. Equação } 1(\mathrm{C}=r . f) \text {, na qual: } \mathrm{C}=\text { constante } \\
\text { obtida pelo produto } r . f=\text { ordem quantitativa das palavras; } f=\text { frequência delas. }\end{array}$ \\
\hline 5 & $\begin{array}{l}\text { 5.1) Após a elaboração da tabela, as palavras de maior frequência foram associadas com string booleanos (and, or, } \\
\text { not, more), por exemplo: termos biológicos and qualidade da água; termos biológicos more Odonata and } \\
\text { qualidade da água. Para associá-los às pesquisas, estão divididos em três seções da literatura: título, resumo e } \\
\text { palavras-chave. }\end{array}$ \\
\hline 6 & $\begin{array}{l}\text { 6.1) Seleção final da Literatura: aplicaram-se os descritores associados às literaturas científicas pré-selecionadas } \\
\text { para as que fossem obtidas apenas aquelas que, em uma das três seções analisas, apresentaram pelo menos } \\
\text { um descritor associado. } \\
\text { 6.2) Análise da aplicabilidade pelos pesquisadores nas literaturas selecionadas para identificar a relação entre os } \\
\text { termos biológicos, a qualidade da água e a Odonata. }\end{array}$ \\
\hline 7 & $\begin{array}{l}\text { A análise estatística dos dados foi realizada com o uso de planilhas eletrônicas contidas no software Excel, versão } \\
2019 \text { (MICROSOFT CORPORATION, 2019). Em seguida aplicou-se a Estatística Descritiva para cálculos de: } \\
\text { frequência absoluta }(f i) \text { e relativa }(f r \%) \text {, média }(\bar{x}) \text { e desvio padrão }(\sigma) \text {. Em seguida, foram elaboradas os } \\
\text { gráficos e tabelas de acordo com o preconizado pelo Instituto Brasileiro de Geografia e Estatística (IBGE, 1993). }\end{array}$ \\
\hline
\end{tabular}

Fonte: Autores (2021).

\section{Resultados e Discussão}

Os dados obtidos e analisados para essa fase indicaram que, nas cinco bases de armazenamento de periódicos após a aplicação dos três descritores seletivos isolados, 49 periódicos possuíam publicações, contendo pelo menos um deles (Quadro $3)$. 
Quadro 3. Rol, em ordem alfabética, e a quantidade de publicações, dos 49 periódicos pré-selecionados após a aplicação dos descritores isolados, no periodo analisado.

\begin{tabular}{|c|c|}
\hline A (4) & $\begin{array}{l}\text { Academia Colombiana de Ciencias Exactas, Físicas y Naturales; Acta Amazonia; Acta Zoologia mexicana; } \\
\text { Ambiente e Água. }\end{array}$ \\
\hline B (10) & $\begin{array}{l}\text { Brasileira de Educação; Brasileira de Meio Ambiente; Brazilian Applied Science Review; Brazilian Journal of } \\
\text { Development.; Biodiversidade Pampeana; Biologia Tropical; Biológico; Biota Neotropical; Boissiera; Boletim } \\
\text { do Museu de Biologia Mello Leitão. }\end{array}$ \\
\hline $\mathbf{C}(\mathbf{5})$ & Caderno Pedagógico; Ceres; Ciência e Saúde; Científica ANAP Brasil; Contexto e Saúde. \\
\hline D (2) & Departamento de Águas e Esgotos; Destaques Acadêmicos. \\
\hline $\mathbf{E}(\mathbf{8})$ & $\begin{array}{l}\text { Eco Debate; Ecología; Ecological Indicators; Eletrônica do Prodema; Enciclopédia Biosfera; Engenharia } \\
\text { Sanitária e Ambiental; Estudos Avançados; Experiências em Ensino de Ciências. }\end{array}$ \\
\hline G (2) & Geociências; Gestão Universitária. \\
\hline H (2) & Hetariana; Holos. \\
\hline I (3) & $\begin{array}{l}\text { Ibero-Americana de Ciências Ambientais; Iniciação Científica da ULBRA; Iniciação Científica, Tecnológica e } \\
\text { Artística. }\end{array}$ \\
\hline $\mathbf{J}(\mathbf{2})$ & Journal of Insect Conservation; Journal of Threatened Taxa. \\
\hline M (3) & Mexicana de Biodiversidade; Multidisciplinary Reviews; Multipliscinary Science Journal. \\
\hline $\mathbf{N}(\mathbf{2})$ & Natureza Online - ESFA; Neotropical Entomology. \\
\hline $\mathbf{O}(\mathbf{1})$ & Oecologia Australis. \\
\hline $\mathbf{P}(\mathbf{3})$ & Pan Amazônica de Saúde; Programa Pós-graduação em Artes da UNB; PUBVET. \\
\hline $\mathbf{S ( 1 )}$ & Scientia Plena. \\
\hline $\mathbf{T}(\mathbf{1})$ & Tecnologia e Ambiente. \\
\hline$\sum=(49)$ & ------------- \\
\hline
\end{tabular}

Fonte: Autores (2021).

Após a seleção dos periódicos, verificou-se que uma pequena parcela $(n=4,0 ; 8,1 \%)$ deles, publicam artigos acerca dos insetos (Acta Zoologia Mexicana; Journal of Insect Conservation, Journal of Threatened Taxa e Neotropical Entomology). Sobre essa especificidade, Hermont et al. (2021) sintetizam que a busca sistemática visa o fornecimento de uma compreensão abrangente do problema. Nessa revisão integrativa, buscaram-se periódicos aptos ao fornecimento dessa especificidade, bem como uma melhor compreensão quanto ao uso de Odonatas com bioindicadora da qualidade da água.

Para identificação do periódico mais prolifero no periodo analisado, Foram analisados os dados obtidos quanto ao


evolução quantitativa, a indicação foi quanto ao ano com o maior número de publicações, ou seja, 2019 (1,2士0,6). No que diz respeito ao quantitativo de publicações, foi efetuado um estudo por Noronha e Ferreira (2000), no município de Belo Horizonte-MG, no qual os autores concluíram que o número de publicações é um dado interessante a ser verificado, pois proporciona informações gerais ou específicas a respeito de um determinado tema.

Em relação ao Século XXI, os dados analisados também indicaram uma produção acadêmica foi mais evolutiva (Figura 1). 
Figura 1. Evolução quantitativa no Século XXI relacionadas ao uso de invertebrados como bioindicadores ambientais.

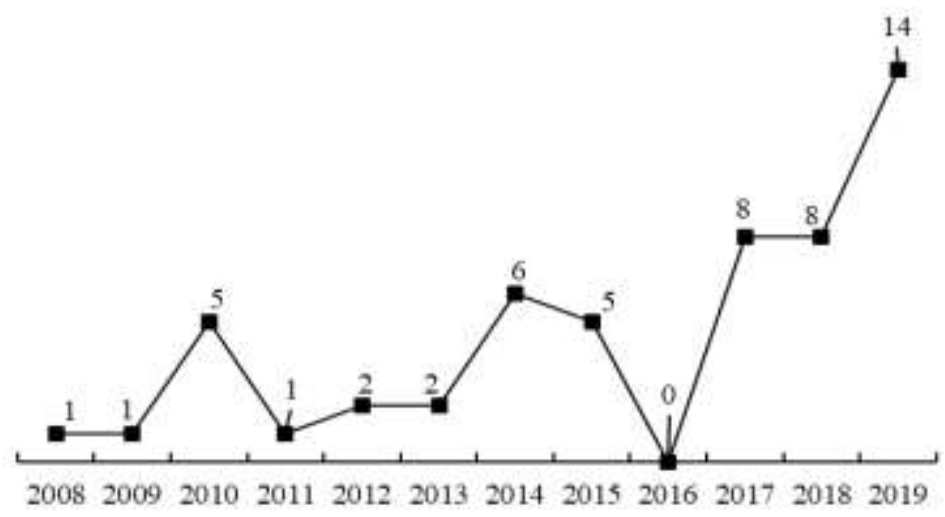

Fonte: Autores (2021).

Os dados indicaram que ocorreram três períodos de estabilidade quantitativa, como se pode observar na Figura 1, entre os anos de 2008-2009; 2012-2013 e 2017-2018. O crescimento real ocorreu nos dois últimos anos do Século XXI (20182019), com um incremento 75\%. Quanto ao crescimento da pesquisa cientifica no território nacional, Dorner et al. (2016) realizaram uma revisão de literatura e concluíram que tem sido observado um incremento no número de artigos científicos desde 2012 (> 46.000), e eles não estão mais unidisciplinares, e sim com grupos de conhecimentos distintos. Nessa revisão, verificou-se que o aumento no número de publicações com esse aspecto ocorreu dois anos após, ou seja, 2014. Logo, essa evolução contribuiu para uma melhor avaliação quanto ao objetivo proposto nesse trabalho.

Então, a aplicação do quantitativo de publicações envolvidos com o tema dessa revisão mostrou-se correta, já que foram obtidas informações específicas acerca do uso da Classe Odonata e a qualidade da água. Todavia, em termos quantitativos, isso ainda não é elevado quando se percebe que a região norte possui a maior bacia hidrográfica e a maior biodiversidade do território nacional.

\subsection{Seleção quanto aos tipos de publicações}

Outro objeto de análise foi o tipo de publicação com a aplicação dos três descritores seletivos nos 49 periódicos, além daqueles publicados em congressos, livros, capítulo de livros, TCC, dissertações, teses e monografias. A análise dos dados indicou a existência de 95 publicações que continham, pelo menos, um deles. Destas, a maior frequência coube aos artigos publicados em periódicos $(n=63,0 ; 66,3 \%)$, seguida de teses de doutoramento (Figura 2). 
Figura 2. Quantitativos dos tipos de publicações pré-selecionadas.

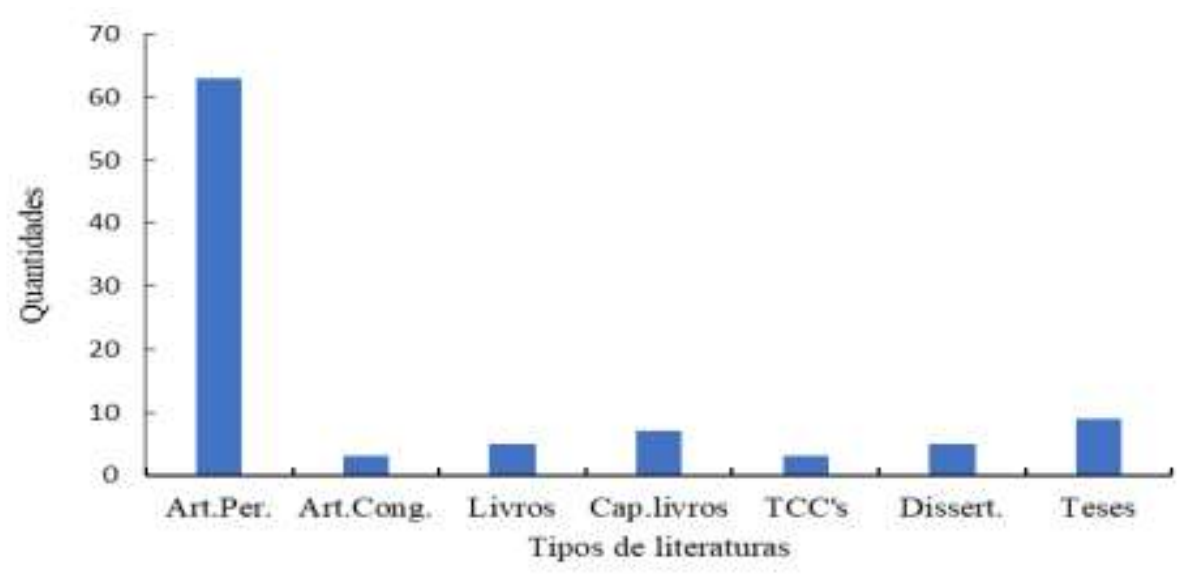

Legendas: Art. Per. Artigos em Periódicos; Art. Cong. Artigos em Congressos; Cap. Livros. Capítulo de Livros; Tcc's. Trabalho de Conclusão de Curso; Dissert. Dissertações; Monogr. Monografias. Fonte: Autores (2021).

Na Figura 2, pode-se observar que dois tipos de publicações obtiveram uma baixa frequência quando comparadas aos demais: arquivos em congressos e TCC's $(n=3,0: 3,2 \%)$. Sobre essas divulgações cientificas, Costa e Perticarrari (2020) realizaram uma pesquisa no município de Itupeva-SP sobre a divulgação científica em livros didáticos (LV) e Texto de Divulgação Cientifica (TDC), e concluiram que, os meios atuais desse tipo de divulgação, implica em compreender, permitem maior interação entre a sociedade e a produção cientifica. Logo, identificar a categoria de divulgação científica, pode sim contribuir para uma interação efetiva entre aqueles dois elementos, independentemente dos números publicados.

\subsection{Frequências dos descritores seletivos isolados nas três seções analisadas}

Os dados obtidos e analisados indicaram que o descritor seletivo "termos biológicos" foi utilizado com maior frequência pelos autores nas três seções analisadas (título, resumo e palavras-chave) das 63 literaturas selecionadas (Tabela 1).

Tabela 1. Frequência dos descritores isolados presentes nas literaturas utilizadas.

\begin{tabular}{cccc}
\hline Ordem $(\mathbf{r})$ & Palavras & $\boldsymbol{f}$ & $\mathbf{C}=\left(\mathbf{r}^{*} \mathbf{f}\right)$ \\
\hline $1^{\mathrm{a}}$ & Odonata & 70 & 70 \\
$2^{\mathrm{a}}$ & Qualidade da água & 94 & 188 \\
$3^{\mathrm{a}}$ & Termos biológicos & 141 & 423 \\
\hline \multicolumn{5}{c}{ Fonte: Autores (2021). }
\end{tabular}

Foi observado também que os descritores intitulados "Odonata" e "qualidade da água", foram utilizados pelos autores com menor frequência quando comparadas ao descritor "termos biológicos". Acerca dessa ordem na Lei de Zipf, Tavares e Celerino (2018) escreveram ser possível quantificar e gerar uma lista com as palavras mais frequentes e ordená-las em rankings ( $r$ ) conforme a quantificação na frequência, ou seja, do menor para o maior valor.

\subsection{Distribuição dos descritores nas três seções analisadas}

A análise dos dados obtidos indicou que as distribuições dos descritores "Odonata", "qualidade da água" e "termos biológicos" possuem frequências similares na sua distribuição nas seções título, resumo e palavras-chave (Tabela 2). 
Tabela 2. Distribuição dos descritores isolados presentes nas literaturas utilizadas.

\begin{tabular}{cccccccc} 
& & \multicolumn{2}{c}{ Título } & \multicolumn{2}{c}{ Resumo } & \multicolumn{2}{c}{ Palavras-chave } \\
\cline { 3 - 8 } Ranking $(\boldsymbol{r})$ & Descritores & $\boldsymbol{f i}$ & $\boldsymbol{f r}(\boldsymbol{\%})$ & $\boldsymbol{f i}$ & $\boldsymbol{f r}(\boldsymbol{\%})$ & $\boldsymbol{f i}$ & $\boldsymbol{f r}(\boldsymbol{\%})$ \\
$1^{\text {a }}$ Ordem & Odonata & 27,0 & 23,4 & 27,0 & 24,1 & 16,0 & 20,5 \\
$2^{\text {a }}$ Ordem & Qualidade da água & 42,0 & 36,5 & 39,0 & 34,8 & 13,0 & 16,6 \\
$3^{\text {a } \text { Ordem }}$ & Termos biológicos* & 46,0 & 40,0 & 46,0 & 41,1 & 49,0 & 62,8 \\
Totais & --------- & 115,0 & 100,0 & 112,0 & 100,0 & 78,0 & 100,0 \\
$\overline{\boldsymbol{x}} \pm \boldsymbol{\sigma}$ & -------- & $38,8 \pm 10,0$ & $33,3 \pm 8,8$ & $37,3 \pm 9,6$ & $33,3 \pm 8,6$ & $26,0 \pm 20,0$ & $33,3 \pm 25,6$ \\
\hline
\end{tabular}

*bioindicadores, macroinvertebrados e insetos. Fonte: Autores (2021).

Observou-se também que o descritor de $1^{\mathrm{a}}$ ordem foi identificado nas três seções das literaturas analisadas, com similaridade quantitativa; na seção palavras-chave, dois descritores (Odonata e qualidade da água) apresentaram significativa diferença estatística $(+4,1 \%)$ entre eles, o que gerou a ordenação que pode visualizada na Tabela 2. A respeito dessa ordenação, um estudo efetuado por Miguéis et al. (2013) na Universidade de Coimbra, em Portugal, descreveu a organização da informação como algo essencial quando se trata da geração de novos conhecimentos, visto que, ao buscar por essas informações em trabalhos acadêmicos, são utilizados termos que no momento da pesquisa podem estar inseridos no título, resumo e/ou palavras-chave. Assim, a utilização de descritores nessa revisão integrativa é de grande importância para obtenção de informação sobre a identificação de termos, cuja similitude corrobora o objeto da revisão.

\subsection{Elaboração dos descritores seletivos associados}

Após a análise dos dados obtidos referentes aos descritores associados, notou-se que a relação entre termos biológicos e qualidade da água foi a mais prolífera nas três seções analisadas ( $n=25,0 ; 65,8 \%)$. Além disso, Odonata e qualidade da água $(n=8,0 ; 21,1 \%)$ foi a segunda mais encontrada, e termos biológicos e Odonata foi a de menor valor $(n=5,0 ; 13,2 \%)$ O ranking obedeceu a lei de Zipf (Tabela 3 )

Tabela 3. Frequência dos descritores associados presentes nas 95 literaturas utilizadas.

\begin{tabular}{|c|c|c|c|c|c|c|}
\hline Ranking & Palavras & Título & Resumo & $\begin{array}{c}\text { Palavras- } \\
\text { chave }\end{array}$ & $f i$ & $f r(\%)$ \\
\hline $1^{\mathrm{a}}$ Ordem & $\begin{array}{c}\text { Termos biológicos* } \\
\text { e Odonata }\end{array}$ & 1 & 2 & 2 & 5,0 & $13,2 \%$ \\
\hline $2^{\mathrm{a}}$ Ordem & $\begin{array}{c}\text { Odonata e Qualidade da } \\
\text { água }\end{array}$ & 0 & 6 & 2 & 8,0 & $21,1 \%$ \\
\hline $3^{\mathrm{a}}$ Ordem & $\begin{array}{l}\text { Termos biológicos* } \\
\text { e Qualidade da água }\end{array}$ & 13 & 10 & 2 & 25,0 & $65,8 \%$ \\
\hline Totais & ----------------------------- & 14 & 18 & 6 & 38,0 & $100 \%$ \\
\hline$\overline{\boldsymbol{x}} \pm \boldsymbol{\sigma}$ & ----------------------------- & $4,7 \pm 7,2$ & $6,0 \pm 4,0$ & $2,0 \pm 0,0$ & $12,7 \pm 10,8$ & $33,4 \pm 28,4$ \\
\hline
\end{tabular}

*Bioindicadores, macroinvertebrados, insetos. Fonte: Autores (2021).

Nesse contexto, o valor para a média das publicações relacionadas com a tríade dessa pesquisa (termos biológicos, qualidade da água e Odonata) foi parco $(0,2 \pm 0,6)$. Então, essa tríade ainda não é um objeto frequente de pesquisas e contribuição para incrementar a análise da qualidade da água. No sul do Brasil, o estudo efetuado por Araújo (2020), no município de Piraquara - PR, envolveu a presença da classe Odonata para análise da qualidade ambiental em um contexto de fauna e flora. Apesar de promover a presença delas em vegetações aquáticas, o estudo não foi específico na relação daquelas com a qualidade da água. 
Em função da relação macroinvertebrados e a qualidade da água, já estão sendo efetuadas pesquisas que associam o uso de fitoplâncton (Ex.: cianobactérias) para incrementar e melhor avaliar a qualidade da água. No semiárido nordestino - CE, Vieira et al. (2020) realizaram uma pesquisa no reservatório de abastecimento e avaliação da dominância dessa bactéria fitoplanctônica e os dados por eles obtidos indicaram que as espécies Cylindrospermopsis raciborskii e Pseudanabaena catenata já apresentam estágios de dominância e abundância, o que pode comprometer a qualidade da água desse local.

\subsection{Seleção final da literatura científica com aplicação dos descritores associados}

Tratando-se de termos biológicos como "bioindicadores", uma minoria apresentou pelo menos uma vez $(n=6,0$; 6,3\%) esse termo entre as 95 literaturas selecionadas. Todavia, houve ocorrência de uma associação entre indicadores biológicos e bioindicadores $(n=1.0 ; 0,6 \%)$. Portanto, não houve evolução quanto ao uso dos invertebrados na função de bioindicadores nas pesquisas cientificas (Quadro 4).

Quadro 4. Rol, em ordem alfabética, das literaturas com a presença dos termos biológicos.

\begin{tabular}{|c|c|c|c|}
\hline Ano & Autor(es) & Título & Periódicos \\
\hline 2019 & $\begin{array}{l}\text { Braz, S. N., \& Longo, R. } \\
\text { M. }\end{array}$ & $\begin{array}{l}\text { Bioindicadores de Poluição Ambiental: um estudo } \\
\text { bibliométrico }\end{array}$ & $\begin{array}{l}\text { Revista Científica ANAP Brasil, 12(27), } \\
42-53\end{array}$ \\
\hline 2015 & Dobler, G. M. et al. & $\begin{array}{c}\text { Artrópodes bioindicadores da qualidade ambiental em } \\
\text { valas de drenagem associadas ao arroio crespo, } \\
\text { Chiapetta, RS }\end{array}$ & Contexto e Saúde, 15(28), 28-31 \\
\hline 2018 & $\begin{array}{l}\text { Fernandes, U. L.; Sousa, } \\
\text { G. F. }\end{array}$ & $\begin{array}{l}\text { Introduzindo conceitos sobre bioindicadores aquáticos } \\
\text { em práticas de educação ambiental } \\
\end{array}$ & $\begin{array}{c}\text { Experiências em Ensino de } \\
\text { Ciências,13(1), 336-348 }\end{array}$ \\
\hline 2017 & $\begin{array}{l}\text { Marques, S. M., Américo- } \\
\text { Pinheiro, J. H. P. }\end{array}$ & Algas como bioindicadores da qualidade da água & $\begin{array}{l}\text { Revista Científica ANAP Brasil, } 10 \\
\text { (19),76-88 }\end{array}$ \\
\hline 2014 & Oliveira, M. A. et al. & $\begin{array}{l}\text { Bioindicadores ambientais: insetos como um } \\
\text { instrumento desta avaliação }\end{array}$ & Ceres, (61),800-807 \\
\hline 2019 & $\begin{array}{l}\text { Prestes, R. M., \& } \\
\text { Vincenci, K. L. }\end{array}$ & Bioindicadores como avaliação de impacto ambiental & $\begin{array}{c}\text { Brazilian Journal of Animal and } \\
\text { Environmental Research, 2(4), 1473-1493 }\end{array}$ \\
\hline 2019 & Sá, R. J. S. et al. & $\begin{array}{l}\text { Indicadores biológicos da qualidade da água e das } \\
\text { mudanças climáticas }\end{array}$ & Multidisciplinary reviews, 2(1),1-8 \\
\hline
\end{tabular}

Fonte: Autores (2021).

Em relação à aplicabilidade, foi verificado que o uso desse termo pode determinar a qualidade ambiental da água ou indicar estado poluitivo, mesmo que seja em valas de drenagem $(n=1,0: 0,6 \%)$, ou então como instrumento de avaliação seja ou não de impacto ambiental, além de servir como ferramenta para a aplicação da Educação Ambiental. Sobre o uso de bioindicadores, Almeida et al. (2019), em uma análise cienciométrica, concluíram que o uso do preditor "bioindicador" já era aplicado desde a década de 90 e, a partir de 2015, houve um incremento de estudos que utilizaram tal preditor. Nessa revisão, eles se fizeram presentes.

Um dos termos biológicos utilizados pelas literaturas cientificas selecionadas foi "macroinvertebrados" $(n=11,0$; $11,6 \%$ ), e foi empregado na maioria deles ( $n=8,0 ; 8,4 \%)$ para identificação da qualidade da água (Quadro 5). 
Quadro 5. Rol, em ordem alfabética das literaturas científicas com o uso do termo biológico "macroinvertebrados".

\begin{tabular}{|c|c|c|c|}
\hline Ano & Autor(es) & Título & Periódicos \\
\hline \multicolumn{4}{|c|}{ Macroinvertebrados } \\
\hline 2009 & $\begin{array}{l}\text { Amorim, A. C. F., } \\
\text { \& Castillo, A. R. }\end{array}$ & $\begin{array}{c}\text { Macroinvertebrados bentônicos como bioindicadores da } \\
\text { qualidade da água do baixo rio Perequê, Cubatão, São } \\
\text { Paulo, Brasil. }\end{array}$ & Biodiversidade Pampeana, 7(1), 16-22 \\
\hline 2018 & Assis, J. V. M. & $\begin{array}{l}\text { Dinâmica da comunidade de macroinvertebrados } \\
\text { bentônicos no baixo rio Xingu durante a fase inicial de } \\
\text { operação da usina hidrelétrica (UHE) de Belo Monte. }\end{array}$ & $\begin{array}{c}\text { Dissertação (Mestrado em Ecologia e Recursos } \\
\text { Naturais). Universidade Federal de São Carlos } \\
\text { - UFSCar }\end{array}$ \\
\hline 2016 & $\begin{array}{l}\text { Barbosa, A. H. S. } \\
\text { et al }\end{array}$ & $\begin{array}{l}\text { Macroinvertebrados bentônicos como bioindicadores da } \\
\text { qualidade da água em um trecho do rio Apodi-Mossoró. }\end{array}$ & Holos, 32(7), 121-132 \\
\hline 2018 & $\begin{array}{l}\text { Braga, C. E. S., \& } \\
\text { Gutjahr, A. L. N. }\end{array}$ & $\begin{array}{c}\text { Inventário e análise dos macroinvertebrados aquáticos } \\
\text { bioindicadores da qualidade da água no rio Uraim, } \\
\text { Paragominas, Pará, Brasil. }\end{array}$ & Enciclopédia Biosfera, 15(28), 1068-1076 \\
\hline 2017 & $\begin{array}{l}\text { Chagas, F. B. et } \\
\quad \text { al. }\end{array}$ & $\begin{array}{l}\text { Utilização da estrutura de comunidades de } \\
\text { macroinvertebrados bentônicos como indicador de } \\
\text { qualidade da água em rios no sul do Brasil. }\end{array}$ & Revista Ambiente \& Água, 12(3), 416-425 \\
\hline 2016 & Conceição, A. A. & $\begin{array}{l}\text { Macroinvertebrados bentônicos como bioindicadores da } \\
\text { qualidade de água em um açude urbano no recôncavo } \\
\text { baiano. }\end{array}$ & $\begin{array}{c}\text { Monografia (Graduação em Biologia). } \\
\text { Universidade Federal do Recôncavo da Bahia } \\
\text { - UFRB }\end{array}$ \\
\hline 2017 & Dias, V. G. et al. & $\begin{array}{l}\text { Macroinvertebrados bentônicos, uma maneira eficaz e } \\
\text { barata de aferição da qualidade da água. }\end{array}$ & $\begin{array}{c}\text { Anais da VIII Mostra Integrada de Iniciação } \\
\text { Científica, } 8(1), 150-151\end{array}$ \\
\hline 2018 & Ramos, C. I. et al. & $\begin{array}{c}\text { Macroinvertebrados aquáticos como bioindicadores da } \\
\text { qualidade da água da bacia hidrográfica Popuca-Botinhas, } \\
\text { Guarulhos (SP). }\end{array}$ & Geociências, 17(1),29-34 \\
\hline 2016 & Roland-Pérez, G. & $\begin{array}{c}\text { Los macroinvertebrados como bioindicadores de la calidad } \\
\text { del agua: cuatro décadas de desarrollo en Colombia y } \\
\text { Latino américa. }\end{array}$ & $\begin{array}{l}\text { Academia Colombiana de Ciencias Exactas, } \\
\text { Físicas y Naturales, } 40(155), 254-274\end{array}$ \\
\hline 2016 & Teixeira, G. M. & $\begin{array}{c}\text { Macroinvertebrados aquáticos da estação ecológica do } \\
\text { Caiuá, Diamante do Norte, Paraná } \\
\end{array}$ & $\begin{array}{l}\text { Tese (Doutorado em Ciências Biológicas). } \\
\text { Universidade Estadual de Londrina - UEL }\end{array}$ \\
\hline 2016 & Saham, L. H. & $\begin{array}{l}\text { Macroinvertebrados aquáticos como bioindicadores em } \\
\text { córregos urbanos do município de Bocaina - SP }\end{array}$ & $\begin{array}{c}\text { Dissertação (Mestrado em Desenvolvimento } \\
\text { Territorial e Meio Ambiente). Centro } \\
\text { Universitário de Araraquara - UNIARA } \\
\end{array}$ \\
\hline
\end{tabular}

Fonte: Autores (2021).

Os dados analisados indicaram que, em quase metade das literaturas, o termo "macroinvertebrados" está associado a outro termo biológico: "bentônicos". Essa associação foi empregada principalmente na verificação da qualidade da água ( $n=$ $5,0 ; 5,2 \%)$ onde foram incluídas as comunidades de macroinvertebrados. Quanto ao emprego desses termos biológicos em trabalhos acadêmicos para identificação da qualidade da água, foi efetuado um estudo no Centro Universitário Cenecista de Osório - RS, por Dias et al. (2017), e eles concluíram que macroinvertebrados são ótimos bioindicadores da qualidade da água devido à alta sensibilidade aos distúrbios ambientais. Já Braz e Longo (2019), em um estudo de revisão bibliográfica, afirmaram que os "termos biológicos" são altamente empregados como ferramenta de análise ambiental, uma vez que que tanto os insetos aquáticos quanto os macroinvertebrados bentônicos são comumente aplicados no biomonitoramento de sistemas aquáticos, de acordo com seus estudos sobre o uso de bioindicadores (animais e vegetais) na qualidade da água.

Para o termo "insetos", a análise dos dados indicou pouco uso nas literaturas selecionadas $(n=1,0 ; 33,3 \%)$. Porém, quando associado ao termo biológico "insetos bentônicos", observou-se um aumento ( $n=2,0 ; 66,6 \%)$. Todavia, em apenas um deles, essa associação foi empregada para verificação da qualidade da água (Quadro 6). 
Quadro 6. Rol, em ordem alfabética, das literaturas científicas com o uso do termo biológico "insetos e insetos bentônicos".

\begin{tabular}{|c|c|c|c|}
\hline Ano & Autor(es) & Título & Periódicos \\
\hline \multicolumn{4}{|c|}{ Insetos e Insetos bentônicos } \\
\hline 2019 & $\begin{array}{l}\text { Campos, T. S. T., \& } \\
\text { Harter-Marques, B. }\end{array}$ & $\begin{array}{l}\text { Insetos bentônicos como indicadores da qualidade da água em } \\
\text { áreas reabilitadas após mineração de carvão a céu aberto no sul } \\
\text { de Santa Catarina, Brasil. }\end{array}$ & Tecnologia e Ambiente, (25), 247-261 \\
\hline 2012 & $\begin{array}{l}\text { Casari, S. A., \& } \\
\text { Constantino R. }\end{array}$ & Insetos do Brasil: diversidade e taxonomia. & Holos, 245-256. \\
\hline 2012 & Monteles, J. S. & $\begin{array}{c}\text { Comunidade de insetos bentônicos em igarapés do Nordeste } \\
\text { Paraense-Amazônia Oriental. }\end{array}$ & $\begin{array}{c}\text { Dissertação (Mestrado em Ciências } \\
\text { Ambientais). Universidade Federal do } \\
\text { Pará - UFPA }\end{array}$ \\
\hline
\end{tabular}

Fonte: Autores (2021).

Percebeu-se também que insetos bentônicos foram utilizados como indicadores da qualidade da água em áreas reabilitadas após mineração de carvão (Campos \& Hartes-Marques, 2020) no sul de Florianópolis - SC. Em Belém-PA, Monteles (2012), fez uso do termo para a identificação da comunidade bentônica, e Casari e Constantino (2012) em Manaus AM, o utilizaram em estudo taxonômico e de diversidade biológica. Tal estudo foi efetuado pela Fundação de Amparo à Pesquisa do Estado do Amazonas, Manaus - AM. Então, ainda há escassez quanto ao uso dos insetos, bentônicos ou não, para indicadores da qualidade da água.

O descritor "qualidade da água" ( $n=10,0 ; 11,5 \%)$, atualmente definido via parâmetros físico-químicos e microbiológicos, é utilizado em pesquisas que visam determinar a qualidade de corpos hídricos seja pelo uso desses parâmetros, seja através de estudos limnológicos e biomonitoramento (Quadro 7). 
Quadro 7. Rol, em ordem alfabética, das literaturas selecionadas que utilizam o descritor Qualidade da água.

\begin{tabular}{|c|c|c|c|}
\hline Ano & Autor(es) & Título & Literaturas \\
\hline 2019 & Alves, L. S. et al. & $\begin{array}{l}\text { Avaliação da qualidade da água na bacia do rio Camaragibe } \\
\text { (Salvador - Brasil): diagnóstico dos parâmetros físico- } \\
\text { químicos, microbiológicos e determinação do IQA. }\end{array}$ & $\begin{array}{l}\text { Revista Brasileira de Meio } \\
\text { Ambiente, 6(1), 71-80 }\end{array}$ \\
\hline 2017 & Carvalho, A. P. M. et al & $\begin{array}{c}\text { Avaliação dos parâmetros de qualidade da água de } \\
\text { abastecimento alternativo no distrito de Jamacaru em } \\
\text { Missão Velha-CE. }\end{array}$ & $\begin{array}{l}\text { Iniciação Científica, Tecnológica } \\
\text { e Artística, 7(1), 35-51 }\end{array}$ \\
\hline 2011 & Jardim, B. F. M. & $\begin{array}{l}\text { Variação dos parâmetros físicos e químicos das águas } \\
\text { superficiais da bacia do rio das velhas-mg e sua associação } \\
\text { com as florações de cianobactérias. }\end{array}$ & $\begin{array}{c}\text { Dissertação (Mestrado em } \\
\text { Saneamento, Meio Ambiente e } \\
\text { Recursos Hídricos). Universidade } \\
\text { Federal de Minas Gerais - UFMG }\end{array}$ \\
\hline 2017 & $\begin{array}{l}\text { Marques, S. M., \& Américo- } \\
\text { Pinheiro, J. H. P. }\end{array}$ & Algas como bioindicadores da qualidade da água. & $\begin{array}{c}\text { Associação Amigos da Natureza } \\
\text { da Alta Paulista, 10(19), 76-88 }\end{array}$ \\
\hline 2016 & Medeiros, A. C. et al. & $\begin{array}{l}\text { Assessment of the quality of water for consumption by } \\
\text { river-bank communities in areas exposed to urban and } \\
\text { industrial pollutants in the municipalities of Abaetetuba and } \\
\text { Barcarena in the state of Pará, Brazil. }\end{array}$ & Ciencia e Saúde, 21(3), 695-708 \\
\hline 2015 & Nogueira, F. F. et al. & $\begin{array}{c}\text { Análise de parâmetros físico-químicos da água e do uso e } \\
\text { ocupação do solo na sub-bacia do Córrego da Água Branca } \\
\text { no município de Nerópolis - Goiás. }\end{array}$ & $\begin{array}{c}\text { Monografia (Graduação em } \\
\text { Engenharia Ambiental e } \\
\text { Sanitária). Universidade Federal } \\
\text { de Goiás - UFG }\end{array}$ \\
\hline 2012 & Oliveira, A. V. S. et al. & $\begin{array}{l}\text { Biomonitoramento da qualidade de água no rio Poxim Açu, } \\
\text { São Cristóvão, Sergipe. }\end{array}$ & $\begin{array}{l}\text { VII Congresso Norte e Nordeste } \\
\text { de Pesquisa e Inovação }\end{array}$ \\
\hline 2018 & Pereira Junior. A. et al & As diatomáceas como indicadoras da qualidade da água. & $\frac{\text { Multidisciplinary Reviews, }}{1-8}, 1(1)$ \\
\hline 2019 & Pereira Junior, A. et al. & $\begin{array}{l}\text { Associação entre Ephemerotera, Plecoptera e Trichoptera e } \\
\text { os parâmetros limnimétricos do índice de qualidade da água. }\end{array}$ & $\begin{array}{l}\text { Brazilian Applied Science } \\
\text { Review, 3(2), 839-863 }\end{array}$ \\
\hline 2019 & Pereira, L. L. et al. & $\begin{array}{l}\text { Análise microbiológica e físico-química de água de poços } \\
\text { no município de Paragominas - PA. }\end{array}$ & Simplíssimo, 2(9), 6-11. \\
\hline 2016 & Pimenta, S. M. et al. & $\begin{array}{l}\text { Estudo da qualidade da água por meio de bioindicadores } \\
\text { bentônicos em córregos da área rural e urbana. }\end{array}$ & Ambiente \& Água, 11(1),198-210 \\
\hline 2017 & Piratoba, A. R. A. et al & $\begin{array}{l}\text { Caracterização de parâmetros de qualidade da água na área } \\
\text { portuária de Barcarena, PA, Brasil. }\end{array}$ & $\begin{array}{c}\text { Revista Ambiente \& Água, } 12 \text { (3), } \\
\text { 435-456 }\end{array}$ \\
\hline 2014 & Pires, T. B. & $\begin{array}{l}\text { Análise de parâmetros físico-químicos e biológicos no } \\
\text { sistema intensivo de produção de Tilápia no Nilo. }\end{array}$ & $\begin{array}{l}\text { Tese (Doutorado em Zootecnia), } \\
\text { Universidade Estadual de } \\
\text { Maringá - UEM }\end{array}$ \\
\hline 2010 & Terra, V. R. et al. & $\begin{array}{l}\text { Estudo limnológico visando avaliação da qualidade das } \\
\text { águas do rio Jucu Braço Norte, ES. }\end{array}$ & Natureza Online, $8(1), 8-13$ \\
\hline
\end{tabular}

Fonte: Autores (2021).

Os dados obtidos e analisados indicaram que, nas pesquisas selecionadas, o descritor "qualidade da água" é aplicado a análises físico-químicos e aos termos biológicos (biológicos e microbiológicos), mas para análise direta daqueles parâmetros. Apenas um deles identificou os invertebrados como potenciais indicadores da qualidade da água (Pereira et al., 2019). Então, ela ainda é objeto de estudo no que diz respeito ao estabelecido na Resolução CONAMA 357 (2005), embora a biota aquática, especialmente invertebrados/insetos aquáticos, faça dos corpos hídricos o habitat natural deles, e apresentem alta sensibilidade às modificações físico-químicas daqueles corpos. Sobre a aplicabilidade desses aspectos na avaliação da qualidade da água, a ANA, em publicação no link oficial dessa agência, relata que há limitações no uso deles, principalmente na identificação para metais pesados, pesticidas e compostos orgânicos.

Sobre esse aspecto, Bruno (2012) realizou uma pesquisa sobre a presença de metais pesados em córregos do Triângulo mineiro - MG, e utilizou larvas de Odonata como bioindicadoras. Portanto, esses invertebrados são potencialmente eficazes na bioindicação da qualidade da água, inclusive com a presença de metais pesados. No que se refere à Odonata, os 
dados obtidos e analisados indicaram que o número de publicações que envolveram esses macroinvertebrados foi elevado $(n=$ 20,0; 21,0\%) quando comparado aos outros dois descritores seletivos (Quadro 8).

Quadro 8. Rol, em ordem alfabética, das literaturas selecionadas a partir da presença do termo Odonata.

\begin{tabular}{|c|c|c|c|}
\hline Ano & Autor(es) & Título & Literaturas \\
\hline 2009 & $\begin{array}{l}\text { Amorim, A. C. F.; } \\
\text { Castillo, A. R. }\end{array}$ & $\begin{array}{c}\text { As ordens Diptera, Hemíptera, Odonata e Coleóptera } \\
\text { são tolerantes necessitando de menor concentração de } \\
\text { oxigênio dissolvido. }\end{array}$ & Biodiversidade Pampeana, 7(1), 16-22 \\
\hline 2010 & $\begin{array}{l}\text { Altamiranda-S, M., et } \\
\text { al. }\end{array}$ & $\begin{array}{c}\text { Composición y preferencia de microhábitat de larvas de } \\
\text { Odonata (Insecta), en la ciénaga San Juan de Tocagua } \\
\text { (Atlántico, Colombia) }\end{array}$ & Ecología, 32(2), 399-410 \\
\hline 2018 & Borges, L. R. & $\begin{array}{c}\text { Diversidade de Odonata e sua relação com diferentes } \\
\text { níveis de perturbação em ambientes aquáticos em uma } \\
\text { área de cerrado do Triângulo Mineiro }\end{array}$ & $\begin{array}{c}\text { Dissertação (Mestrado em Ecologia e } \\
\text { Conservação de Recursos Naturais) } \\
\text { Universidade Federal de Uberlândia - } \\
\text { UFU }\end{array}$ \\
\hline 2018 & Calvão, L. B. et al. & $\begin{array}{l}\text { Land use modifies Odonata diversity in streams } \\
\text { of the Brazilian Cerrado }\end{array}$ & $\begin{array}{c}\text { Journal of Insect Conservation, } \\
22(2018), 675-685\end{array}$ \\
\hline 2016 & Calvão, L. B. & $\begin{array}{l}\text { Padrão de distribuição de Odonata (Insecta) em } \\
\text { sistemas aquáticos com exploração de madeira na } \\
\text { Amazônia Oriental: seleção de microhabitat e } \\
\text { características morfológicas das libélulas. }\end{array}$ & $\begin{array}{l}\text { Tese (Doutorado em Zoologia), } \\
\text { Universidade Federal do Pará - UFPA }\end{array}$ \\
\hline 2014 & Consatti, G. et al. & $\begin{array}{l}\text { Presença de Odonata em áreas preservadas e não } \\
\text { preservadas nas matas ciliares do rio Taquari, RS }\end{array}$ & $\begin{array}{l}\text { Revista de Iniciação Científica da } \\
\text { ULBRA, (12), 57-65 }\end{array}$ \\
\hline 2013 & Damaceno, I. V. et al. & $\begin{array}{l}\text { Levantamento de Odonata (Insecta) ao longo das } \\
\text { margens do rio Dois de Setembro, Município de } \\
\text { Ecoporanga, noroeste do Estado do Espírito Santo }\end{array}$ & $\begin{array}{l}\text { Boletim do Museu de Biologia Mello } \\
\text { Leitão, (33), 25-33. }\end{array}$ \\
\hline 2019 & $\begin{array}{l}\text { García Junior, M. D. et } \\
\text { al. }\end{array}$ & $\begin{array}{c}\text { The diversity of Odonata adults's at Pampa Biome } \\
\text { from Brazil }\end{array}$ & $\begin{array}{c}\text { Revista de Biologia Tropical, 67(1), } \\
\text { 107-117. }\end{array}$ \\
\hline 2015 & $\begin{array}{l}\text { Godé, L. \& P. F. } \\
\text { Peruquetti. }\end{array}$ & $\begin{array}{c}\text { Libélulas (Odonata) da Reserva Biológica de Pedra } \\
\text { Talhada. }\end{array}$ & Editora Boissiera (68), 199-203. \\
\hline 2014 & Hanauer, G. et al. & $\begin{array}{c}\text { Inventariamento preliminar da fauna de libélulas } \\
\text { (Odonata) em quatro municípios do Vale do } \\
\text { Taquari/RS }\end{array}$ & $\begin{array}{c}\text { Revista Destaques Acadêmicos, 6(3), } \\
36-45\end{array}$ \\
\hline 2013 & $\begin{array}{l}\text { Kulkarni, A. S., \& } \\
\text { Subramanian, K. A. }\end{array}$ & $\begin{array}{l}\text { Habitat and seasonal distribution of Odonata (Insecta) } \\
\text { of Mula and Mutha river basins, Maharashtra, India }\end{array}$ & $\begin{array}{l}\text { Journal of Threatened Taxa, } 5 \text { (7), } \\
\text { 4084-4095 }\end{array}$ \\
\hline 2017 & Miguel, T. B. et al & $\begin{array}{c}\text { Odonata (Insecta) as a tool for the biomonitoring of } \\
\text { environmental quality }\end{array}$ & $\begin{array}{c}\text { Ecological Indicators, } 81 \text { (2017), 555- } \\
566\end{array}$ \\
\hline 2019 & $\begin{array}{l}\text { Oliveira-Junior, J. M. } \\
\text { B., \& Juen, L. }\end{array}$ & $\begin{array}{c}\text { The Zygoptera/Anisoptera Ratio (Insecta: Odonata): A } \\
\text { New Tool for Habitat Alterations Assessment in } \\
\text { Amazonian Streams }\end{array}$ & Neotropics Entomology, 48(4), 552-560 \\
\hline 2012 & Neiss, U. G. & $\begin{array}{c}\text { Taxonomia de Odonata (Insecta), com ênfase na } \\
\text { caracterização morfológica e biologia de larvas, na } \\
\text { Amazônia Central, Brasil }\end{array}$ & $\begin{array}{l}\text { Tese (Doutorado em Entomologia), } \\
\text { Instituto Nacional De Pesquisas Da } \\
\text { Amazônia - INPA. }\end{array}$ \\
\hline 2012 & Pereira, M. C. S. A. & $\begin{array}{c}\text { Diversidade de libélulas (Insecta: Odonata) em área de } \\
\text { vegetação natural no município de Barroso, Minas } \\
\text { Gerais }\end{array}$ & $\begin{array}{l}\text { Monografia (Graduação em Ciências } \\
\text { Biológicas). Universidade Federal de } \\
\text { Minas Gerais - UFMG }\end{array}$ \\
\hline 2015 & Rodrigues, I. S. et al. & $\begin{array}{c}\text { Odonatas registradas no rio Catolé Grande, no } \\
\text { município de Itapetinga, BA }\end{array}$ & $\begin{array}{l}\text { Revista Enciclopédia Biosfera, 11(21), } \\
\text { 2352-2364 }\end{array}$ \\
\hline 2018 & Santos, D. M. et al. & $\begin{array}{c}\text { Odonatofauna (Insecta: Odonata) do córrego São José } \\
\text { em Tagará da Serra-MT }\end{array}$ & $\begin{array}{l}\text { Revista Gestão Universitária, } \\
\text { 10(2018),1-9 }\end{array}$ \\
\hline 2017 & Silva Filho, E. S. & $\begin{array}{l}\text { Eficiência de ninfas de libélula (Odonata) como } \\
\text { potenciais predadores de larvas de Aedes aegypti, em } \\
\text { condições laboratoriais em São Cristóvão, Sergipe. }\end{array}$ & $\begin{array}{c}\text { Monografia (Graduação em Tecnologia } \\
\text { em Agroecologia). Instituto Federal de } \\
\text { Educação, Ciência e Tecnologia de } \\
\text { Sergipe - IFS }\end{array}$ \\
\hline 2018 & Silva, E. C. et al. & $\begin{array}{l}\text { Diversidade de Odonata (Insecta) em igarapés na } \\
\text { Reserva Extrativista Tapajós-Arapiuns (PA) }\end{array}$ & $\begin{array}{l}\text { Revista Ibero Americana de Ciências } \\
\text { Ambientais, } 9(6), 109-119\end{array}$ \\
\hline
\end{tabular}




\begin{tabular}{|c|c|c|c|}
\hline 2018 & Tavares, R. I. S. & $\begin{array}{c}\text { A influência da complexidade e cor do ambiente sobre } \\
\text { o comportamento de emergência e seleção de habitat } \\
\text { em Odonata }\end{array}$ & $\begin{array}{c}\text { Dissertação (Mestrado em Ecologia e } \\
\text { Recursos Naturais). Universidade } \\
\text { Federal de São Carlos - UFSCar }\end{array}$ \\
\hline
\end{tabular}

Fonte: Autores (2021).

A partir dos dados obtidos e analisados, foi observado que a classe Odonata foi pouco citada nas literaturas como bioindicadora de alterações na qualidade da água $(n=4,0 ; 4,2 \%)$. Além do mais, essa classe contribui para a saúde pública, uma vez que são predadoras de larvas do A. aegypti $(n=1,0 ; 0,6 \%)$. Como bioindicadoras ambientais, estudos pioneiros já identificaram a sensibilidade às modificações ocorridas no ambiente. Ferreira-Peruquetti e De Marco Júnior (2002) verificaram que elas ocupam posição superior quando se observa a cadeia alimentar e podem ser utilizadas como um indicativo da alteração ambiental.

Sobre isso, Peruquetti (2004) efetuou um estudo em torno de uma plantação de cana-de-açúcar (Saccharum officinarum) em Jataí-SP, concluindo que, onde houve supressão da mata ciliar e prática de monocultivo, a riqueza de espécies dessa classe sofre um incremento significativo. Afirma também que no represamento hídrico, esse efeito se repete. Isso corrobora o sintetizado por Nessimiam et al. (2008) acerca da existência de espécies que apresentam restrições quanto às condições ambientais e ecológicas. O estudo efetuado por Dobler et al. (2015), no município de Chiapetta-RS, concluiu que os insetos da ordem Odonata (como macroinvertebrados bentônicos) são mais abundantes em sua coleta, porém, ainda há trabalhos científicos que não promovem tal interligação.

\section{Conclusão}

A biologia tem fornecido dados importantes aos gestores ambientais e aos pesquisadores da área, pois pode e está sendo utilizada em diversos tipos de análises, como na exploração e na conservação de recursos naturais, além do monitoramento de áreas tanto de terra firme quanto aquáticas, além das comunidades.

A Classe Odonata ainda apresenta baixa frequência de aplicabilidade para biomonitoramento, ou seja, em casos de alterações ecológicas e nas propriedades físico-química dos recursos naturais, especialmente a água. Ainda assim, há muitos estudos preliminares sobre a utilização desse método.

Por isso, recomenda-se que os estudiosos da relação invertebrados-meio ambiente, em especial a dos ecossistemas aquáticos, possam observar a presença desses indivíduos com maior atenção à classe Odonata, considerando-a ferramenta de indicação dos distúrbios, alterações, perturbações e até degradações nesses ambientes.

\section{Referências}

Altamiranda-S, M., Pérez, L. A. G., \& Gutiérrez, M. L. C. (2010). Composición y preferencia de microhábitat de larvas de Odonata (Insecta), en la ciénaga San Juan de Tocagua (Atlántico, Colombia). Ecología, 32 (2), 399-410. https://www.researchgate.net/publication/262754677_Compositi on_and_microhabitat_preference_of_Odonata_larvae_insecta_in_the_San_Juan_de_Tocagua_swamp_Atlantico_Colombia

Almeida, J. R., Souza, R. C., Azevedo, F. M., Cagni, G. S., \& Lizama, M. L. A. P. O uso de bioindicadores no monitoramento da qualidade dos recursos hídricos. In: Encontro Internacional de Produção Científica. 11. 2019. Anais eletrônicos. http://rdu.unicesumar.edu.br/bitstream/1234567 89/3678/1/Raquel\%20Cosin\%20de\%20Souza.pdf

Alves, L. S., Martins, L. A., \& Jesus, L. B. (2019). Avaliação da qualidade da água na bacia do rio Camaragibe (Salvador - Brasil): diagnóstico dos parâmetros físico-químicos, microbiológicos e determinação do IQA. Revista Brasileira de Meio Ambiente, 6(1) 071-080. https://revistabrasileirademeioambiente.com/index.php/RVBMA/article/view/203/172

Amorim, A. C. F., \& Castillo, A. R. (2009). As ordens Diptera, Hemíptera, Odonata e Coleóptera são tolerantes necessitando de menor concentração de oxigênio dissolvido. Revista Biodiversidade Pampeana, 7(1) 16-22. https://revistaseletronicas.pucrs.br/index.php/biodiversidadepampeana/article/view/5454

ANA. (2011). Monitoramento da qualidade da água em rios e reservatórios. Educação a distância: Hidrologia e Qualidade da Água. ANA. 
Anelli, R. L. S. (2015). Uma nova cidade para as águas urbanas. Revista Estudos Avançados, 29(84) 69 - 84. https://www.scielo.br/pdf/ea/v29n84/0103-4014ea-29-84-00069.pdf

Araújo, B. R. (2020). Taxonomia e diversidade das libélulas (Insecta: Odonata) do Mananciais da Serra, município de Piraquara, estado do Paraná, Dissertação (Mestrado em Ciências Biológicas), Universidade Federal do Paraná. https://acervodigital.ufpr.br/bitstream/handle/1884/69143/R\%20-\%20D\%20\%20BRENO\%20RODRIGO\%20DE\%20ARAUJO.pdf?sequence=1\&isAllowed=y

Assis, J. V. M. (2018). Dinâmica da comunidade de macroinvertebrados bentônicos no baixo rio Xingu durante a fase inicial de operação da usina hidrelétrica (UHE) de Belo Monte. Dissertação (Mestrado em Ecologia e Recursos Naturais). Universidade Federal de São Carlos - São Paulo. https://repositorio.ufscar.br/handle/ufscar/10171

Barbosa, A. H. S., Silva, C. S. P., Araújo, S. E., Lima, T. B. B., \& Dantas, I. M. (2016). Macroinvertebrados bentônicos como bioindicadores da qualidade da água em um trecho do rio Apodi Mossoró. Revista Holos, 7(32) 121-132. http://www2.ifrn.edu.br/ojs/index.php/HOLOS/article/view/4183/1592, https://dx.doi.org/10.15628/holos.2016.4183

Borges, L. R. (2018). Diversidade de Odonata e a sua relação com diferentes níveis de perturbação em ambientes aquáticos em uma área de Cerrado do Triângulo Mineiro. Dissertação (Mestrado em Conservação de Recursos Naturais). Universidade Federal de Uberlândia, Belo Horizonte. https://repositorio.ufu.br/bitstream/123456789/21240/2/DiversidadeOdonataRela\%C3\%A7ao.pdf

Botelho, L. L. R., Cunha, C. C. A., Macedo, M. (2011). O método da revisão integrativa nos estudos organizacionais. Gestão e Sociedade, 5(11),121-136. https://www.gestaoesociedade.org/gestaoesociedade/article/view/1220, https://dx.doi.org/10.21171/ges.v5i11.1220

Braga, C. E. S., \& Gutjahr, A. L. N. (2018). Inventário e análise dos macroinvertebrados aquáticos bioindicadores da qualidade da água no rio Uraim, Paragominas, Pará, Brasil. Revista Enciclopédia Biosfera, 15(28) 1068-1076. https://www.conhecer.org.br/enciclop/2018B/BIO/Inventario.pdf

Branco, S. M. (1995). Conflitos conceituais nos estudos sobre meio ambiente. Revista Estudos Avançados, 9(23) 217-223. https://www.scielo.br/scielo.php?script=sci_arttext\&pid=S0103-40141995000100014, https://dx.doi.org/10.1590/S0103-40141995000100014

Brasil, L. S., \& Vilela, D. S. (2019). Peculiaridades regionais na percepção de brasileiros sobre libélulas: nomenclatura popular e conservação. Revista HETAERINA, $\quad 1(1) \quad$ 15-20. https://www.researchgate.net/publication/330597999_Peculiaridades_regionais_na_percepcao_de_bra sileiros_sobre_libelulas_nomenclatura_popular_e_conservacao

Braz, S. N., \& Longo, R. M. (2019). Bioindicadores de Poluição ambiental: um estudo bibliométrico. Revista ANAP Brasil, $12(27) 42$ - 53. https://www.amigosdanatureza.org.br/publicacoes/index.php/anap_brasil/article/view/2239/2082

Bruno. C. G. C. (2012). Avaliação da contaminação de córregos de Cerrado por metais pesados utilizando-se larvas de Odonata como bioindicadores. Dissertação (Mestrado em Ecologia e Conservação de Recursos Naturais). - IUniversidade Federal de Uberlândia - MG https://repositorio.ufu.br/bitstream/123456789/13367/1/d.pdf

Calvão, L. B. (2016). Padrão de distribuição de Odonata (Insecta) em sistemas aquáticos com exploração de madeira na Amazônia Oriental: seleção de microhabitat e características morfológicas das libélulas. Tese (Doutorado em Zoologia), Universidade Federal do Pará - Pará. repositorio.ufpa.br/jspui/bitstream/2011/8748/1/Tese_PadraoDistribuicaoOdonata.pdf

Calvão, L. B. (2018). Land use modifies Odonata diversity in streams of the Brazilian Cerrado. Journal of Insect Conservation, 22 (2018), 675-685. https://link.springer.com/article/10.1007/s10841-018-0093-5, https://dx.doi.org/10.1007/s10841-018-0093-5

Camargo, F. C., Iwamoto, H.H., Galvão, C. M., Pereira, G. A., Andrade, R. B. \& Masso, G. C. (2018). Competências e barreiras para Prática Baseada em Evidências na enfermagem: revisão integrativa. Revista Brasileira de Enfermagem, 7(4),2148-2156. https://www.scielo.br/pdf/reben/v71n4/pt_0034-7167reben-71-04-2030.pdf. http://dx.doi.org/10.1590/0034-7167-2016-0617

Campos, T. S. T., \& Harter-Marques, B. (2019). Insetos bentônicos como indicadores da qualidade da água em áreas reabilitadas após mineração de carvão a céu aberto no sul de Santa Catarina, Brasil. Revista Tecnologia e Ambiente, (25), 247-261. http://periodicos.unesc.net/tecnoambiente/article/view/3483/pdf

Carvalho, A. P. M., Silva, J. N., Santos, V. S., Ferraz, R. R. (2017). Avaliação dos parâmetros de qualidade da água de abastecimento alternativo no distrito de Jamacaru em Missão Velha-CE. Revista de Iniciação Científica, Tecnológica e Artística, 7 (1), 35-51. http://www1.sp.senac.br/hotsites/blogs/revistainiciacao/wp-content/uploads/2017/11/4-226_IC_ArtigoRevisado.pdf

Casari, S. A., \& Constantino, R. (2012). Insetos do Brasil: diversidade e taxonomia. Ribeirão Preto: Holos.

Chagas, F. B., Rutkoski, C. F., Bieniek, G. B., Vargas, G. D. L. P., Hartmann, P. A., \& Hartmann, M. T. (2017). Utilização da estrutura de comunidades de macroinvertebrados bentônicos como indicador de qualidade da água em rios no sul do Brasil. Revista Ambiente \& Água, 12(3) 416-425. https://www.scielo.br/pdf/ambiagua/v12n3/1980-993X-ambiagua-12-03-00416.pdf , https://dx.doi.org/10.4136/smbi-agua.2015

Conceição, A. A. (2016). Macroinvertebrados bentônicos como bioindicadores da qualidade de água em um açude urbano no recôncavo baiano. Monografia (Graduação em Biologia). Universidade Federal do Recôncavo da Bahia - Bahia. www.repositoriodigital.ufrb.edu.br/bitstream/123456789/1446/1/TCCAdreani Araujo da Conceição.pdf

Consatti, G., Santos, D. M., Renner, S., \& Périco, E. (2014). Presença de Odonata em áreas preservadas e não preservadas nas matas ciliares do rio Taquari, RS. Revista de Iniciação Científica da ULBRA, Canoas, (12) 57-65. http://www.periodicos.ulbra.br/index.php/ic/article/view/1062/977

Costa, W. M., Perticarrari, A. A (2020). Contribuição do texto de divulgação cientifica no processo de ensino e aprendizagem dos ciclos biogeoquímicos. Ciências da Natureza e suas Tecnologias, 5(2), 923-943. http://periodicos.cfs.ifmt.edu.br/periodicos/index.php/rpd/article/view/681/376. http://dx.doi.org/10.23926/RPD.2526-2149.2020.v5.n2.p922-943.id681

Damaceno, I. V., Buys, S. C., Silva, C. C., \& Martins, R. F. (2013). Levantamento de Odonata (Insecta) ao longo das margens do Rio Dois de setembro, Município de Ecoporanga, noroeste do Estado do Espírito Santo. Boletim do Museu de Biologia Mello Leitão, (33) 25-33. 
Dias, V. G., Silva, V. F., Souza, T. C. (2017). Macroinvertebrados bentônicos, uma maneira eficaz e barata de aferição da qualidade da água. VIII Mostra Integrada de Iniciação Científica, 8(1) 150. https://www.arca.fiocruz.br/bitstream/icict/10066/2/ivani_damacenoetal_IOC_2014.pdf

Dobler, G. H., Reis, E., \& Ferreira, F. W. (2015). Artrópodes bioindicadores da qualidade ambiental em valas de drenagem associadas ao arroio crespo, Chiapetta, RS. Revista Contexto \& Saúde. 15(28) 28 - 31. https://www.revistas.unijui.edu.br/index.php/contextoesaude/article/view/3032

Dorner, S. H., Wissmann, M. A., Silveira, M. S., \& Schmidt, C. M. (2016). Cooperação científica: uma análise da rede formada pelos pesquisadores do programa de pós graduação em Desenvolvimento Regional e Agronegócio da Unioeste. Revista Capital Científico, 14(2), 1-16. https://revistas.unicentro.br/index.php/capitalcientifico/article/viewFile/3856/3000

Ferreira-Peruquetti, P. S., \& De Marco Júnior, P. (2002). Efeito da alteração ambiental sobre as comunidades de Odonata em riachos de Matra Atlântica de Minas Gerais, Brasil. Revista Brasileira de Zoologia, 19(2),317-327. https://www.scielo.br/j/rbzool/a/nKQ9DBLqTdStVLt7q4DcDrq/?lang=pt\&form at=pdf\#: : :text=O\%20sistema\%201\%C3\%B3tico\%20\%C3\%A9\%20o,sofrendo\%20com\%20a\%20a\%C3\%A7\%C3\%A3o\%20antr\%C3\%B3pica.\&text=Entretan to $\% 2 \mathrm{C} \% 20$ no $\% 20 \mathrm{Brasi} \% 2 \mathrm{C} \% 20$ ainda $\% 20 \% \mathrm{C} 3 \% \mathrm{~A} 9$, sobre $\% 20$ as $\% 20$ comunidades $\% 20 \mathrm{de} \% 20$ Odonata. https://dx.doi.org/10.1590/S10181752002000200002

García Junior, M. D. N., Rakes, M., Pazini, J. B., Pasini, R. A., Garcia. F. R. M., \& Grützmacher, A. D. (2019). The diversity of Odonata adults at Pampa Biome from Brazil. Revista Biologia Tropical, 67(1) 107-117. https://www.scielo.sa.cr/pdf/rbt/v67n1/0034-7744-rbt-67-01-107.pdf, https://dx.doi.org/10.15517/rbt.v67i1.33285

Gode, L., Peruquetti, P. F. (2015). Libélulas (Odonata) da Reserva Biológica de Pedra Talhada. In: Studer, A., L. Nusbaumer, R. Spichiger (Eds.). Biodiversidade da Reserva Biológica de Pedra Talhada (Alagoas, Pernambuco - Brasil.). Boissiera (68),199-203. Biodiv_PT_BR_6.6.1.pdf (anitastuder.org)

Hanauer, G., Renner, S., Périco, E. (2014). Inventariamento preliminar da fauna de libélulas (Odonata) em quatro municípios do Vale do Taquari/RS. Revista Destaques Acadêmicos, 6(3) 36-45. http://www.univates.br/revistas/index.php/destaques/article/view/412/404

Hermont, A. P., Zina, L. G., Silva, K. D., Silva, J. M., \& Martins-Junior, P. A. (2021). Revisões integrativas: conceitos, planejamento e execução. Arquivos em Odontologia, 57, 3-7. file:///D:/2021/Artigos\%20submetidos/Research\%20Society\%20and\%20Development/Annanda\%20e\%20Vito/25571Texto\%20do\%20artigo-92014-1-10-20210310.pdf. http://.dx.doi.org/10.7308/aodontol/2021.57.e01

IBGE. (1993). Normas de apresentação tabular. (3a ed.). Brasília: IBGE

Jardim, B. F. M. (2011). Variação dos parâmetros físicos e químicos das águas superficiais da bacia do Rio das Velhas-MG e sua associação com as florações de cianobactérias. Dissertação (Mestrado em Saneamento, Meio Ambiente e Recursos Hídricos. Universidade Federal de Minas Gerais, BH. https://repositorio.ufmg.br/bitstream/1843/ENGD-8KDPVL/1/disserta_o_b_rbara_fernanda_de_melo_jardim.pdf

Kulkarni, A. S., Subramanian, K. A. (2013). Habitat and seasonal distribution of Odonata (Insecta) of Mula and Mutha river basins, Maharashtra, India. Journal of Threatened Taxa, 5 (7), 4084-4095. https://www.threatenedtaxa.org/index.php/JoTT/article/view/997, https://dx.doi.org/10.11609/JoTT.o3253.4084-95

Lakatos, E. M., \& Marconi, M. A. (2017). Metodologia do trabalho científico. (8a ed). Atlas

Maia, E. L. S. (1973). Comportamento bibliométrico da língua portuguesa, como veículo de representação da informação. Ciência da Informação, 2(2), 99138. http://revista.ibict.br/ciinf/article/view/31/31

Marques, S. M., \& Américo-Pinheiro, J. H. P. (2017). Algas como bioindicadores da qualidade da água. Revista Associação Amigos da Natureza da Alta Paulista (ANAP Brasil), 10(19), 76-88. file:///C:/Users/Adm/Downloads/1651-3310-1-SM.pdf

Medeiros, A. C., Lima, M. O., \& Guimarães, R. M. (2016). Avaliação da qualidade da água de consumo por comunidades ribeirinhas em áreas de exposição a poluentes urbanos e industriais nos municípios de Abaetetuba e Barcarena no estado do Pará, Brasil. Revista Ciência \& Saúde Coletiva, 21(3) 695708.https://www.scielo.br/pdf/csc/v21n3/1413-8123-csc-21-03-0695.pdf https://dx.doi.org/10.1590/1413-81232015213.26572015

MICROSOFT CORPORATION. (2019). Project for Windows. Versão Excel 2019. Microsoft Corporation, Albuquerque. New México.

Miguéis, A., Neve, B., Silva, A. L., Trindade, A., \& Bernardes, J. A. (2013). A importância da palavras-chave dos artigos científicos da área das Ciências Farmacêuticas, depositados no Estudo Geral: estudo comparativo com os termos atribuídos na MEDLINE, Revista Científica de Informação e Documentação, 4(2), 112-125. https://www.revistas.usp.br/incid/article/view/69284/71742 http://dx.doi.org/10.11606/issn.2178-2075.v4i2p112-125

Miguel, T. B., Oliveira-Junior J..B., Ligeiro, R., \& Juen, 1. (2017). Odonata (Insecta) as a tool for the biomonitoring of environmental quality. Ecological Indicators, (81), 555-566. https://www.sciencedirect.com/science/article/abs/pii/S1470160X17303539, https://dx.doi.org/10.1016/j.ecolind.2017.06.010

Monteles, J. S. (2012). Comunidade de insetos bentônicos em igarapés do Nordeste Paraense-Amazônia Oriental. Dissertação (Mestrado em Ciências Ambientais). Universidade Federal do Pará - Pará. repositorio.ufpa.br/jspui/bitstream/2011/6845/1/Dissertacao_ComunidadeInsetosBentonicos.pdf

Neiss, U. G. (2012). Taxonomia De Odonata (Insecta), com ênfase na caracterização morfológica e biologia de larvas, na Amazônia Central, Brasil. Tese( Doutorado em Ciências Biológicas - Entomologia). Instituto Nacional de Pesquisas da Amazônia. https://bdtd.inpa.gov.br/handle/tede/2078\#: : text=NEISS\%2C\%20Ulisses\%20Gaspar., \%3A\%20\%5Bs.n.\%5D\%2C\%202012.\&text=Tese\%20(Ci\%C3\%AAncias\%20Biol\%C3\%B3gicas\%20(Entomologia) ),Nacional\%20de $\% 20$ Pesquisas $\% 20 \mathrm{da} \% 20 \mathrm{Amaz} \% \mathrm{C} 3 \%$ B 4 nia.

Nessimiam, J. L., Venticinque, E. M., Zuanon, J., De Marco Júnior, P., Gordo, M., Fidelis, L., Batista J. D., \& Juen L. (2008). Land use, habitat integrity, and aquatic insect assemblages in Central Amazonian streams. Hydrobiologia, (614),117-131. https://link.springer.com/article/10.1007/s10750-008-9441-x, https://dx.doi.org/10.1007/s10750-008-9441-x

Noronha, D. P., Ferreira, S. M. (2000). Revisões de literatura. In: Campello, Bernadete Santos, Condón, Beatriz Valadares, Kremer, Jeannette Marguerite (Orgs.) Fontes de informação para pesquisadores e profissionais. Universidade Federal de Minas Gerais - UFMG. Revisão de Literatura e Desenvolvimento Científico: conceitos e estratégias para confecção - PDF Download grátis (docplayer.com.br) 
Oliveira, A. V. S., Araujo, C. S., Pereira, T. P. B., \& Dantas J. O. (2012). Biomonitoramento da qualidade da água no rio Poxim Açu, São Cristóvão, Sergipe. VII Congresso Norte e Nordeste de Pesquisa e Inovação. https:/propi.ifto.edu.br/ocs/index.php/connepi/vii/paper/viewFile/3115/1554

Oliveira, M. A., Gomes, C. F. F., Pires, E. M., Marinho, C. G. S., \& Della Lucia, T. M. C. (2014). Bioindicadores ambientais: inseto como instrumento desta avaliação. Revista Ceres, (61) 800-807. https://www.scielo.br/j/rceres/a/wwYgZqFJftwbBcKPNNDfwKq/?format=pdf\&lang=pt https://dx.doi.org/10.1590/0034-737x20142000005

Oliveira-Junior, J. M. B., Juen, L. (2019). The Zygoptera/Anisoptera Ratio (Insecta: Odonata): A New Tool for Habitat Alterations Assessment in Amazonian Streams. Neotropical Entomology, 48(4) 552-560. https://reader.elsevier.com/reader/sd/pii/S1470160X21000534?token=C3833EFFE3FA088 1FD80CF691 495 F366E233B6B4110BE04EAACD0E09EFC621996BB7057BD78565A85231FC9FDE4EE024\&originRegion=us-east-1\&originCreation=20210510 225733

Pereira Junior. A., Holanda, L. B., Silva, A. C. S., Farias, N. S. N., Moura, A. J. S., \& Silva, L. P. (2018). As diatomáceas como indicadoras da qualidade da água. Multidisciplinary reviwes, 1(1) 1-8. file://C:/Users/Bio/Desktop/404990-cecde697ff484c02bfeb5426760a6624.pdf, https://dx.doi.org/10 .29327/mult i. 2018012

Pereira, A. S., Shitsuka, D. M., Parreira, F. J., \& Shitsuka, R. (2018). Metodologia da Pesquisa Científica. UFSM.

Pereira, L. L. Silveira, A. S., Gonçalves, A. F., Cristo, J. P., Nunes, J, I. S., Ribeiro, R. P., \& Pereira Júnior, A. (2019). Análise microbiológica e físico-química de águas de poços no município de Paragominas - PA. In: Pereira Junior, A., Jesus, E. S. As múltiplas visões do meio ambiente e os impactos ambientais, 2 (9), 6-11. http://doi.editoracubo.com.br/10.4322/978-85-455202-1-4-09 https://dx.doi.org/10.4322/978-85-455 202-1-4-09

Pereira, M. C. S. A. (2012). Diversidade de libélulas (Insecta: Odonata) em área de vegetação natural no município de Barroso, Minas Gerais. Monografia (Graduação em Ciências Biológicas). Universidade Federal de Lavras - MG. https://saojoaodelreitransparente.com.br/files/docs/MONOGRAFIA.pdf Peruquetti, P. S. F (2004). Odonata (libélulas) do município de Luís Antônio, São Paulo, Brasil: relação com o uso do solo e riqueza faunística. Tese (Doutorado em Ciências Biológicas) $\quad-\quad$ Universidade Federal de São Carlos, São Paulo, 2004. https://repositorio.ufscar.br/bitstream/handle/ufscar/1777/TesePSFP.pdf?sequence=1.

Pimenta, S. M., Boaventura, G. R., Peña, A. P., \& Ribeiro, T. G. (2016). Estudo da qualidade da água por meio de bioindicadores bentônicos em córregos da área rural e urbana. Revista Ambiente \& Água, 11(1) 198-210. https://www.scielo.br/pdf/ambiagua/v11n1/1980-993X-ambiagua-11-01-00198.pdf , https://dx.doi.org/10.4136/ambi.agua.1672

Piratoba, A. R. A., Ribeiro, H. M. C., Morales, G. P., \& Gonçalves, W. G. (2017). Caracterização de parâmetros de qualidade da água na área portuária de Barcarena, PA, Brasil. Revista Ambiente \& Água, 12 (3), 435-456. https://www.scielo.br/j/ambiagua/a/f45JMMTdfXvPWLmM6mbDX6K/abstract/?lang=pt, https://dx.doi.org/10.4136/ambi-agua.1910

Prestes, R. M., \& Vincenci, K. L. (2019). Bioindicadores como avaliação de impacto ambiental. Revista Brazilian Journal of Animal and Environmental Research, 2(4) 1473-1493. https://www.brazilianjournals.com/index.php/BJAER/article/view/3258/3128

Ramos, C. I., Rosini, E. F., Vargas, R. R., \& Azevedo, F. D’A. (2018). Macroinvertebrados aquáticos como bioindicadores da qualidade da água da bacia hidrográfica Popuca-Botinhas, Guarulhos (SP). Revista Geociências, 17(1) 29-34. http://revistas.ung.br/index.php/geociencias/article/view/3062/2558\#

Rodrigues, I., Maciel, C. M., Maciel Júnior, A., Diniz, A., \& Souza, L. (2015). Odonatas registradas no rio catolé grande, no município de Itapetinga, BA. Revista Enciclopédia Biosfera, 11(21) 2352-2364. http://www.conhecer.org.br/enciclop/2015b/biologicas/Odonatas\%20registradas.pdf

Roland-Pérez, G. (2016). Los macroinvertebrados como bioindicadores de la calidad del agua: cuatro décadas de desarrollo en Colombia y Latino américa. Revista Academia Colombiana de Ciencias Exactas, Físicas y Naturales. 40(155) 254-274. http://www.scielo.org.co/pdf/racefn/v40n155/v40n155a07.pdf

Sá, R. J. S., Souza, A. G. S., Jesus. E. S., \& Pereira Júnior, A. (2019). Indicadores biológicos de qualidade da água e as mudanças climáticas. Revista Multidisciplinary reviews, 2 (1), $1-8 . \quad$ https://www.malquepub.com/multi-e2019006\#: :text=RESUMO\%20Uma\%20esp\%C3\%A9cie \%20\%C3\%A9\%20um,das\%20a\%C3\%A7\%C3\%B5es\%2C\%20associadas\%20a\%20elas, https://dx.doi.org/10.29327/multi.2019006

Santos, D. M., Nunes, J. R. S., Arruda, N. D., Pinheiro, A. S. B., Nunes, P. A. S. S., \& Flores, A. (2018). Odonatofauna (Insecta: Odonata) do córrego de São


http://www.gestaouniversitaria.com.br/system/scientific_articles/files/000/000/416/original/Res_Exp_Daniela.pdf?1530676033

Silva, E. C., Silva, T. R., Ló, J. S., Lima, A. K. A., \& Oliveira Júnior, L. M. B. (2018). Diversidade de Odonata (Insecta) em igarapés na Reserva Extrativista Tapajós-Arapiuns (PA). Revista Ibero Americana de Ciências Ambientais, 9 (6), 109-119. http://www.sustenere.co/index.php/rica/article/view/CBPC21796858.2018.006.0013, https://dx.doi.org/10.6008/CBPC2179-6858.2018.006.0013

Silva Filho, E. S. (2017). Eficiência de ninfas de libélula (Odonata) como potenciais predadores de larvas de Aedesaegypti, em condições laboratoriais em São Cristóvão, Sergipe. Trabalho de Conclusão de Curso (Curso Superior Técnico Agrícola) - Instituto Federal de Educação, Ciência e Tecnologia de Sergipe, São Cristóvão. https://repositorio.ifs.edu.br/biblioteca/bitstream/123456789/293/1/Edivaldo\%20Santos\%20da\%20Silva\%20Filho.pdf

Silva, J. A., Ferreira, J. R., Almeida, L. O., Silva, H. P. B. (2018). Poluição em rios urbanos: o caso do rio Capibaribe em Limoeiro - PE. In: Congresso Nacional De Educação, 5, Pernambuco. Anais eletrônicos file:///C:/Users/Adm/Downloads/MODELO\%20DA\%20REVISTA.pdf

Soares, C. B., Hoga, L. A. K., Peduzzi, M., Sangaleti, C. Yonekura, T., Silva, D. R. A. D. (2014). Revisão integrativa: conceitos e métodos utilizados em enfermagem. Revista da Escola de Enfermagem, São Paulo, 48(2) 335-345. https://www.scielo.br/pdf/reeusp/v48n2/pt_0080-6234-reeusp-48-02-335.pdf

Souza, M. T., Silva, D., \& Carvalho, R. (2010) Revisão integrativa: o que é e como fazer. Einstein, 8(1),102-106. https://www.scielo.br/pdf/eins/v8n1/pt_1679-4508-eins-8-1-0102.pdf.

Tavares, R. I. S. (2018). A influência da complexidade e cor do ambiente sobre o comportamento de emergência e seleção de habitat em Odonata. Dissertação (Mestrado em Ecologia e Recursos Naturais). Universidade Federal de São Carlos - São Paulo. https://repositorio.ufscar.br/handle/ufscar/9619?show=full 
Research, Society and Development, v. 10, n. 9, e24910917605, 2021

(CC BY 4.0) | ISSN 2525-3409 | DOI: http://dx.doi.org/10.33448/rsd-v10i9.17605

Teixeira, G. M. (2016). Macroinvertebrados aquáticos da estação ecológica do Caiuá, Diamante do Norte, Paraná. Tese (Doutorado em Ciências Biológicas). Universidade Estadual de Londrina - Paraná. 10_projeto.pdf (iat.pr.gov.br)

Tavares, W. Q., Celerino, V. G., (2018). A importância da Bibliometria para a Indexação Automática, Revista Folha de rosto em Biblioteconomia e Ciência da Informação, 4(1), 7-14. https://periodicos.ufca.edu.br/ojs/index.php/folhaderosto/article/download/273/287/

Terra, V. R. Pratte-Santos. R., Aliprandi. R. B., Barcelos, F. B., Martins, J. L. D., Azevedo Júnior, R., \& Barbieri. R. S. (2010). Estudo limnológico visando avaliação da qualidade das águas do rio Jucu Braço Norte, ES. Revista Natureza Online, 8 (1), 8-13. www.naturezaonline.com.br/natureza/conteudo/pdf/02_terravretal_0813.pdf

Zanella, L. (2012). A questão ambiental na visão de biólogos em formação continuada. Revista Brasileira de Educação Ambiental, 7(2) 3743.file://C:/Users/Adm/Downloads/1770-Texto\%20do\%20artigo-10216-1-10-20130812 http://dx.doi.org/ 10.34024/revbea.2012.v7.1770 